\title{
Influence of chronic inflammation on Bcl-2 and PCNA expression in prostate needle biopsy specimens
}

\author{
MICHAEL GLOVER $^{1 *}$, SHARDUL SONI $^{1 *}$, QINGHU REN $^{2}$, \\ GREGORY T. MACLENNAN ${ }^{2,3}$, PINGFU FU $^{3,4}$ and SANJAY GUPTA ${ }^{1,3,5,6}$
}

\begin{abstract}
Departments of ${ }^{1}$ Urology and ${ }^{2}$ Pathology, Case Western Reserve University; ${ }^{3}$ Division of General Medical Sciences, Case Comprehensive Cancer Center; ${ }^{4}$ Department of Epidemiology and Biostatistics, Case Western Reserve University;

${ }^{5}$ The Urology Institute, University Hospitals Cleveland Medical Center; ${ }^{6}$ Department of Urology,

Louis Stokes Cleveland Veterans Affairs Medical Center, Cleveland, OH 44106, USA
\end{abstract}

Received December 28, 2016; Accepted March 17, 2017

DOI: $10.3892 / 01.2017 .6668$

\begin{abstract}
The association between inflammation and cancer has been established in certain forms of human malignancies; however, its role in prostate cancer remains unclear. The present study investigates a possible association between chronic inflammation and the development of epithelial neoplasia in the prostate. Needle biopsy specimens were obtained from patients with serum prostate-specific antigen levels $>4 \mathrm{ng} / \mathrm{ml}$, evaluated for morphological findings, and immunostained for $\mathrm{Bcl}-2$ and proliferating cell nuclear antigen (PCNA). $\mathrm{Bcl}-2$ is a survival protein that appears to lie at a nodal point in pathways involved in cell survival, carcinogenesis, and development of therapeutic resistance in certain cancer types. Similarly, PCNA is a critical protein for DNA replication, repair of DNA damage, chromatin structure maintenance, chromosome segregation and cell-cycle progression. The association between these two proteins was examined in prostate tissues with and without chronic inflammation, as well as tissues with and without evidence of neoplastic changes. Of the 106 needle biopsies examined, 18\% exhibited atrophy with inflammation. Proliferative inflammatory atrophy/post-atrophic hyperplasia were observed in $42 \%$, high-grade prostatic intraepithelial neoplasia (HGPIN) in $8 \%$, prostatic adenocarcinoma in
\end{abstract}

Correspondence to: Professor Sanjay Gupta, Department of Urology, Case Western Reserve University, Wood Research Tower RTG01, 2019 Adelbert Road, Cleveland, OH 44106, USA

E-mail: sanjay.gupta@case.edu

*Contributed equally

Abbreviations: PCNA, proliferating cell nuclear antigen; PIA, proliferative inflammatory atrophy; $\mathrm{PAH}$, post-atrophic hyperplasia; HGPIN, high-grade prostatic intraepithelial neoplasia; GSTP1, glutathione S-transferase pi

Key words: chronic inflammation, prostate cancer, needle biopsy, proliferative inflammatory atrophy, post atrophic hyperplasia, prostate-specific antigen
$11 \%$, and $2 \%$ had atypical acinar proliferation suspicious for malignancy. A total of 36 specimens were stained for Bcl-2 and PCNA. Bcl-2 was expressed widely in inflammatory and epithelial tissue; however, more intense expression was observed in the areas of chronic inflammation, predominantly in infiltrating immune cells. The highest proliferation index was observed in the epithelia of HGPIN and cancer. An inverse correlation between the expression of Bcl-2 and the expression of PCNA was observed in the epithelium. The areas of chronic inflammation were associated with increased Bcl-2 expression, whereas the highly proliferative epithelium minimally expressed $\mathrm{Bcl}-2$. These results suggest that Bcl-2 alters the phenotype of particular epithelial cells with a gain in neoplastic characteristics, leading to a likely precursor that may later progress into HGPIN and cancer.

\section{Introduction}

Persistent chronic inflammation has emerged as a potential risk factor in the development of carcinoma of several organ types, including liver, large bowel, urinary bladder, gastric mucosa, lung, colon and pancreas (1-3). Experimental evidence suggests that longstanding chronic inflammation promotes prostate carcinogenesis $(4,5)$. In fact, a positive link between clinical history of prostatitis and increased relative risk of prostate cancer has been documented among 70,000 North American men (6). Chronic inflammation is frequently identified in prostate biopsies, radical prostatectomy specimens and tissue resected from benign prostatic hyperplasia $(7,8)$. A number of possible etiological factors have been proposed in the development of chronic inflammation in the prostate, including dietary imbalances, exposure to environmental pollutants, alterations in testosterone:estrogen ratio, pathogen infection, race or genetic alterations (9-12). The resulting microenvironment, characterized by the accumulation of various types of immune cells, generates reactive oxygen and nitrogen species, inducing oxidative stress in proliferating epithelium that may interact with DNA to generate permanent genomic alterations (13). Extensive research efforts have been undertaken to investigate a possible link between inflammation and the development of prostate cancer $(14,15)$. We previously reported the effect of 
chronic inflammation on prostate carcinogenesis in a 5-year follow-up study of needle biopsy specimens from 177 patients with clinical parameters suspicious for malignancy. In follow-up biopsies over a 5-year period, $20 \%$ of patients with only chronic inflammation on initial biopsy exhibited a new diagnosis of adenocarcinoma, and an additional $6 \%$ exhibited high-grade prostatic intraepithelial neoplasia (HGPIN) lesions; by contrast, among patients initially showing no inflammation, only $6 \%$ subsequently developed cancer (16).

In recent years, an injury-and-regeneration model has been proposed suggesting that repeated bouts of injury to the prostatic epithelium, presumably as a result of inflammation in response to pathogens or autoimmune disease and/or dietary factors, results in proliferation of epithelial cells that possess a phenotype intermediate between basal cells and mature luminal cells (17). These alterations may result in the modulation of a delicate balance between cell proliferation and cell death. A defect in the normal regulation of programmed cell death by a subset of cells that are able to survive and continue to proliferate may favor the acquisition of further genetic alterations that would promote the development of malignancy. A current hypothesis is that morphological changes in acinar or ductal epithelia result from the continuous influence of inflammation (18). These findings are characterized as HGPIN, a lesion that is a putative precursor of prostatic adenocarcinoma. A pathological entity of chronic inflammation accompanied by focal glandular atrophy and epithelial cell proliferation, termed proliferative inflammatory atrophy (PIA) and post-atrophic hyperplasia $(\mathrm{PAH})$, has been recognized $(19,20)$. PIAs are atrophic lesions frequently observed in the peripheral zone of the prostate, occasionally adjacent to the foci of HGPIN and cancer (19). It has been hypothesized that the atrophic epithelial cells in PIA lesions are the targets of neoplastic transformation and potentially give rise to carcinoma. PAH has been shown to be closely associated with persistent chronic inflammation (21). PAH represents 'post-inflammatory' atrophic lesions. It is hypothesized that proliferative regeneration of secretory cells following disruption of the epithelium may generate small, hyperplastic glands arranged in a lobular configuration, which is a typical feature of PAH. PAH is occasionally confused with carcinoma due to its overlapping architectural and nuclear features. In particular, these lesions are predominantly composed of small crowded glands, usually surrounded by centrally situated and dilated large ducts, irregular and atrophic-appearing contours lined by flattened-to-cuboidal epithelial cells, with nuclear enlargement and prominent nucleoli $(21,22)$. PIA/PAH lesions have been reported to show increased proliferative activity compared with benign prostatic epithelium and simple atrophy (SA) (23). The signs as well as other morphological evidence may suggest the transition from a PIA/PAH lesion to the development of HGPIN; however, the molecular evidence for cell survival and proliferation under the influence of chronic inflammation is lacking. To gain knowledge in this area, the present study examined the morphology of 106 needle-biopsy specimens. Immunohistochemistry was used to investigate the association between the expression of Bcl-2, a cell survival protein that plays a role in apoptosis by blocking programmed cell death (24), and the expression of proliferating cell nuclear antigen (PCNA), a proliferation marker (25). The results suggest an inverse correlation between the expression of
Bcl-2 and that of PCNA in epithelial cells under the influence of chronic inflammation. Since, in our opinion, PAH represents the end result of longstanding PIA, these morphological lesions were grouped together and designated as PIA/PAH lesions for the sake of the present analysis.

\section{Materials and methods}

Prostate biopsy material. The study was performed in formalin-fixed, paraffin-embedded prostate biopsy specimens obtained between August 2001 to June 2003 from male patients aged $>40$ years who had serum prostate-specific antigen levels of $>4 \mathrm{ng} / \mathrm{ml}$. Needle biopsies were performed at the University Hospitals Cleveland Medical Center (Cleveland, OH, USA). Specimens from all ethnic groups were included. The study was approved by the Institutional Review Board (08-03-38) at the University Hospitals Cleveland Medical Center.

Characterization of extent and intensity of inflammatory findings. All specimens were examined by two expert urological pathologists (QR and GTM) for the presence and distribution of chronic inflammatory infiltrate, which was assigned a score of 1 (mild), 2 (moderate), 3 (strong) or 4 (very strong), as previously reported (16). The degree of inflammation was assigned according to the approximate percentage of stroma and glands in the biopsy specimen involved by aggregates of $\geq 50$ lymphocytes, or by granulomatous inflammation on a scale of mild inflammation (1-10\% involvement), moderate inflammation (11-50\% involvement) and severe/strong inflammation ( $>50 \%$ involvement). A total of 106 hematoxylin and eosin-stained needle-biopsy specimens were examined.

Classification of prostatic lesions. Prostatic needle-biopsy specimens were further evaluated and categorized for foci of SA, PIA and/or PAH, HGPIN, and cancer. The morphology of these lesions and the criteria for their diagnosis are well-established, and readily found in standard journals of surgical pathology $(26,27)$.

Immunohistochemistry. Immunohistochemical staining for Bcl-2 and PCNA was performed in 36 needle-biopsy specimens previously categorized in groups as SA, PIA/PAH, HGPIN and cancer, using standard techniques. Paraffin-embedded prostate needle-biopsy specimens were cut at a 4- $\mu \mathrm{m}$ thickness and the sections were incubated with target retrieval solution (cat. no. S2367; Dako; Agilent Technologies, Inc., Santa Clara, CA, USA) in a steamer for $45 \mathrm{~min}$. The sections were permeabilized in a solution containing $100 \mathrm{mM}$ Tris $(\mathrm{pH} 7.5)$, $150 \mathrm{mM} \mathrm{NaCl}, 0.5 \%$ blocking agent, $0.3 \%$ Triton $\mathrm{X}$ and $0.2 \%$ saponin for $20 \mathrm{~min}$ at room temperature. Sections were incubated overnight in a humid chamber at $4^{\circ} \mathrm{C}$ with antibodies against Bcl-2 (cat. no. M0887; Dako; Agilent Technologies, Inc.) at 1:50 dilution. Control sections were incubated with antisera in the presence of 10-fold excess of these antibodies or with isotype-matched IgG (cat. no. sc-516102; Santa Cruz Biotechnology Inc., Dallas, TX) in normal goat serum (cat. no. 927502; BioLegend, Inc., San Diego, CA) for $30 \mathrm{~min}$ at room temperature. Subsequent to washing three times in TBS, detection was achieved using standard HRP-labeled LSAB2 system (cat. no. K0609; Dako; Agilent Technologies, 
Inc.), with 3-3-diaminobenzidine as the chromogen. For PCNA (cat. no. sc-71858; Santa Cruz Biotechnology, Inc.), the immunoreactive complexes were detected using AEC+ substrate-chromogen from the Dako EnVision+ System (cat. no. K4002; Dako; Agilent Technologies, Inc.), consisting of 3-amino-9-ethylcarbazole as the chromogen. Slides were then counterstained in Mayer's hematoxylin, mounted in crystal mount media, and dried overnight on a level surface, as previously described (28).

Scoring of stained cells. The immunostained sections were examined independently by the pathologist (QR) and co-investigators (MG and SS) using light microscopy. Sections were viewed under an Olympus BH2 inverted microscope (Olympus Corporation, Tokyo, Japan) and images were acquired with Image-Pro Plus v.7 software (Media Cybernetics Rockville, MD, USA) and digitally stored on a computer. The intensity of immunohistochemical staining for Bcl-2 was scored as 0 (negative), 1 (weak), 2 (moderate) or 3 (intense). Bcl-2 staining was heterogeneous, exhibiting areas with intense staining and other areas with moderate-to-weak staining. Because the majority of the observed lesions were heterogeneous, the overall score assigned represented the average for the entire lesion. The PCNA staining was scored by counting the positively stained cells and total number of cells, quantified in random microscopic field with a minimum 500-cell count (magnification, $\mathrm{x} 40$ ) with the assistance of a software program (Olympus Microsuite v.5; Olympus America Inc. Center Valley, PA). A minimum of four screenshots per specimen, representing individual microscopic fields, were counted for determining the tissue staining distribution.

Statistical analysis. Statistical analysis was performed using Kruskal-Wallis test, a nonparametric test based on Wilcoxon scores, to examine the median differences in Bcl-2 and PCNA among the four subcategories of tissues (SA, PIA/PAH, HGPIN and cancer), followed by pair-wise comparison of any two tissue types where the P-value was not adjusted for multiple comparisons. The association between various grades of inflammation (mild, moderate, strong and very strong) with Bcl-2 and PCNA was also estimated using Spearman correlation coefficient. All tests were two-sided and $\mathrm{P}<0.05$ was considered to indicate a statistically significant difference.

\section{Results}

As shown in Table I, of the 106 specimens examined, 20\% (20/106) showed unremarkable prostatic tissue, $8 \%(8 / 106)$ of specimens exhibited SA, whereas $42 \%(45 / 106)$ of cases showed PIA/PAH lesions. HGPIN was observed in $8 \%(8 / 106)$ of specimens, and adenocarcinoma was diagnosed in $11 \%(12 / 106)$ of specimens. Additionally, 2\% (2/106) of the specimens exhibited atypical small acinar proliferations, suspicious for, but not diagnostic of, malignancy. Representative images of these lesions observed from needle biopsies are shown in Fig. 1A-D.

Bcl-2 protein expression. A total of 36 needle biopsy specimens that contained areas of inflammation were randomly selected for equivalent portions of strong/very strong, moderate or mild/absent inflammatory infiltrates detected in the biopsy
Table I. Characteristics and evaluation of prostate needle-biopsy specimens $(n=106)$.

\begin{tabular}{lrr}
\hline Type & $\mathrm{n}$ & $\%$ \\
\hline No glandular abnormality & 12 & 11 \\
Atrophy without inflammation & 8 & 8 \\
Simple atrophy & 19 & 18 \\
PIA/PAH & 45 & 42 \\
HGPIN & 8 & 8 \\
Cancer & 12 & 11 \\
Others $^{\text {a }}$ & 2 & 2 \\
\hline
\end{tabular}

${ }^{a}$ Others include glandular hyperplasia, granuloma, adenomatous hyperplasia and/or acinar proliferation. PIA/PAH, proliferative inflammatory atrophy/post-atrophic hyperplasia; HGPIN, high-grade prostatic intraepithelial neoplasia.

core for various lesions and stained for Bcl-2 by immunohistochemistry (Fig. 2A-D). The samples were analyzed for the percentage of cells expressing Bcl-2 as well as intensity of expression. The average intensity of the stain was graded from 0 (no expression) to 3 (strong expression). In these samples, basal epithelial cells exhibited prominent Bcl-2 staining, which was noted to be in close proximity to the inflammatory lesions, with $77.1 \%$ of basal epithelial cells showing strong expression. However, negative-to-weak Bcl-2 expression was noted in the majority of luminal epithelial cells ( $>90 \%)$, with heterogeneous staining pattern in the normal/benign areas. Average epithelial cell stain intensity was in the low-medium range (mean, 1.67). The immune cells in the specimens also expressed Bcl-2, but only $38.2 \%$ exhibited immunoreactivity to this antigen. The immune cells expressing Bcl-2 exhibited a higher staining intensity (mean, 2.04) than the epithelial cells. Cytoplasmic Bcl-2 expression was almost exclusively observed amongst epithelial cells, whereas immune cells were observed to have extensive Bcl-2 expression within the nucleus. Only $3.7 \%$ of inflammatory cells and epithelial cells in areas adjacent to but not involved by inflammation showed Bcl-2 expression, with an average staining intensity of 0.95 . Compared to SA (7.0\%), the highest percentage (17.4\%) of Bcl-2-positive cells was observed in PIA/PAH lesions $(\mathrm{P}<0.0001)$, followed by HGPIN (10.1\%) and cancer lesions (9.2\%), respectively (Fig. 3A).

PCNA protein expression. The staining for the proliferative marker PCNA was also examined in the prostate needle-biopsy specimens (Fig. 2A-D). In normal/benign glands, PCNA expression was more often noted in the basal epithelial cells, than in the luminal epithelial cells. The proliferation index analyzed from numerous microscopic fields revealed a progressive increase in proliferation index in epithelial cells from SA to cancer. Compared to SA $(2.8 \%)$, a significant increase in PCNA was observed in PIA/PAH (4.4\%), HGPIN (8.1\%) and cancer $(17.6 \%)(\mathrm{P}<0.0001)$, respectively (Fig. 3B).

Relationship between Bcl-2 and PCNA expression. A negative correlation was observed within the serial specimens stained for PCNA and Bcl-2. Cells expressing Bcl-2 were observed to 
SA
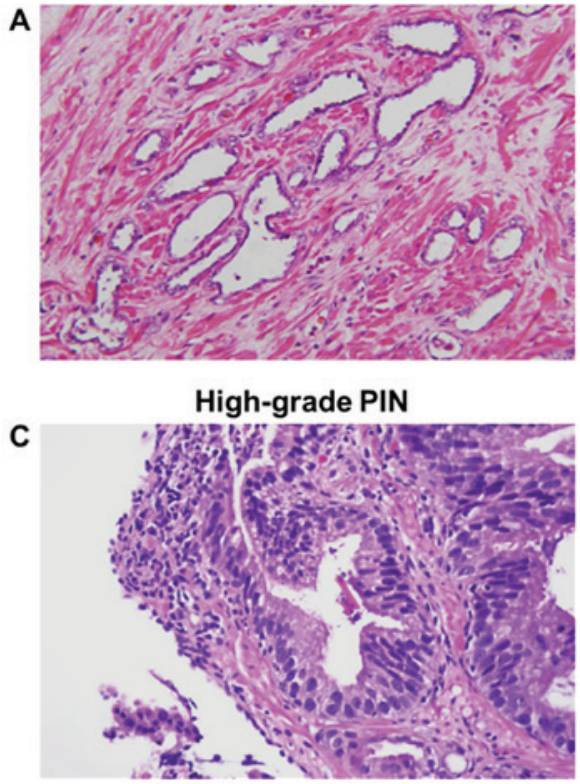

PIA/PAH
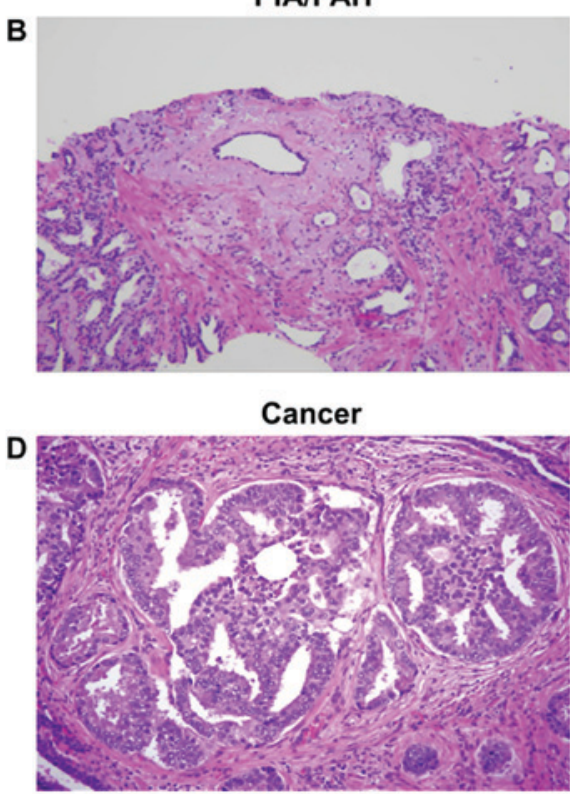

Figure 1. Pathological findings in needle-biopsy specimens by hematoxylin and eosin staining. (A) Prostate tissue with an area of SA, and some small and some dilated glands. The glands are lined by small cuboidal cells with bland nuclei and minimal cytoplasm. (B) Prostate tissue with PIA and PAH lesions. Crowded, irregular, atrophic glands with abundant chronic inflammatory infiltrate in the surrounding stroma are visible in the PIA (left), whereas PAH lesions show a dilated central acinus flanked by numerous small and large atrophic acini in a lobular pattern, distorted by sclerotic stroma, which exhibits prominent inflammatory cell infiltrate (right). (C) High-grade PIN involving a large pre-existing duct. Chronic inflammation is present in the stroma (center) is concentrated around another large duct (right). (D) Prostatic adenocarcinoma with cribriform structures. Magnification, x20. SA, simple atrophy; PIA, proliferative inflammatory atrophy; PAH, post-atrophic hyperplasia; PIN, prostatic intraepithelial neoplasia.

SA

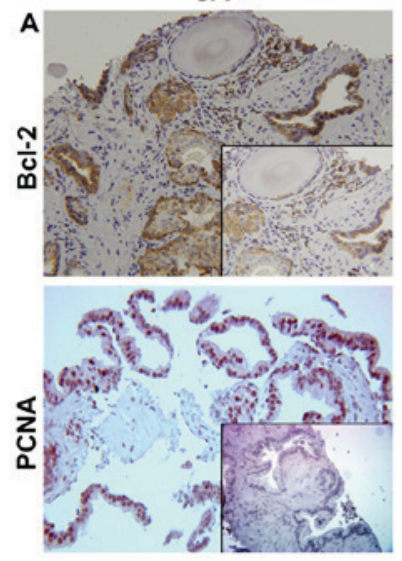

PIA/PAH
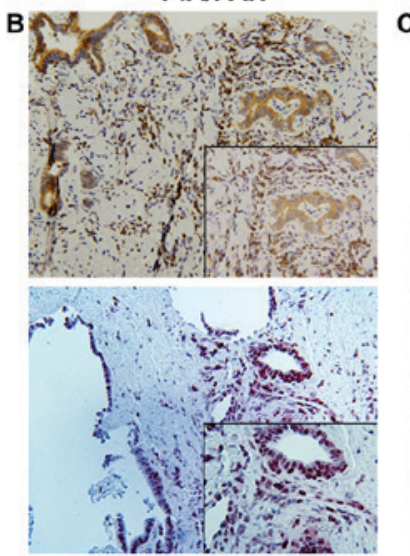

High-grade PIN
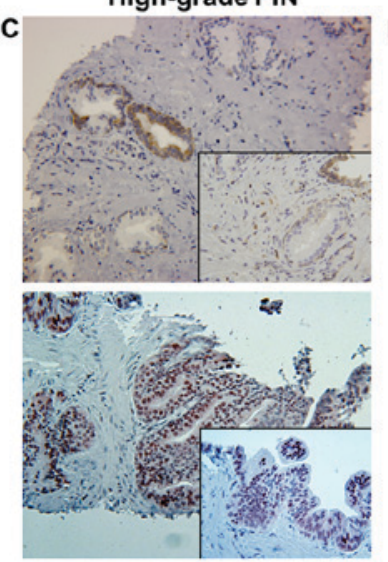

Cancer
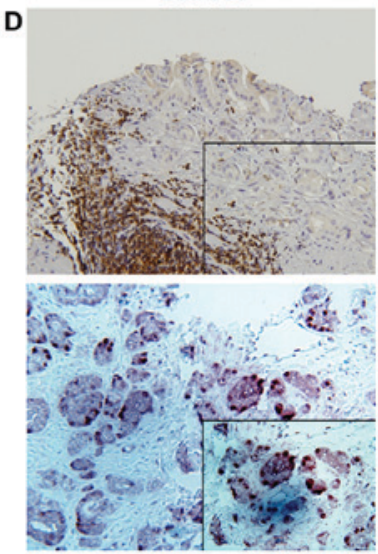

Figure 2. Immunohistochemical staining for Bcl-2 and PCNA in needle-biopsy specimens within (A) SA, (B) PIA/PAH lesions, (C) high-grade PIN and (D) cancer. Bcl-2 is widely expressed in inflammatory and epithelial tissues of SA and PIA/PAH, with more intense staining in the basal epithelial cells near the areas of chronic inflammation, as well as predominantly in infiltrating immune cells. High expression of PCNA is observed in the proliferating epithelium in high-grade PIN and cancer. Magnification, x20 (inset, x40). PCNA, proliferating cell nuclear antigen; SA, simple atrophy; PIA, proliferative inflammatory atrophy; PAH, post-atrophic hyperplasia; PIN, prostatic intraepithelial neoplasia.

have low levels or an absence of PCNA expression. A similar association was observed in samples that exhibited high PCNA expression, wherein little-to-no Bcl-2 expression was detected. PCNA stainings was observed within the nucleus among epithelial cells, as compared with the predominant cytoplasmic staining observed in epithelial cells stained for Bcl-2. Immune infiltrate cells did not express high levels of PCNA as compared with the Bcl-2 expression (Fig. 4A and B).

Relationship between inflammation, cell survival and neoplastic progression. Subsequently, the correlation between inflammation, cell survival and neoplastic progression was assessed with regard to the Bcl-2 and PCNA scoring by a pathologist. (Fig. 5). As shown in Fig. 5A, a strong positive association between inflammation and $\mathrm{Bcl}-2$ expression was observed $(\mathrm{r}=0.88 ; \mathrm{P}<0.0001)$ suggesting that cell survival increases with the increasing inflammation. A negative association $(r=-0.197 ; P=0.249)$ between inflammation and proliferation was identified (Fig. 5B), suggesting that prolonged inflammation facilitates the initiation of normal prostate epithelial cells through increased survival, which then gain independence to proliferate and progress to malignancy. 

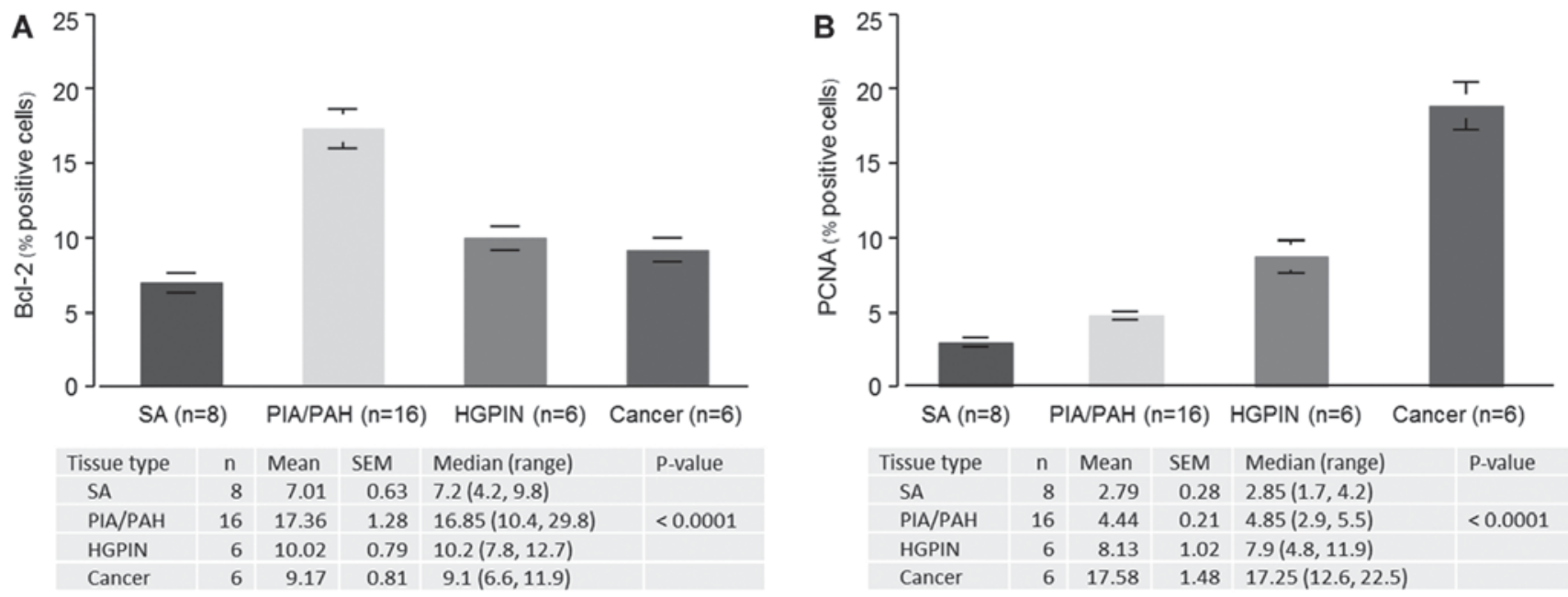

Figure 3. Distribution of Bcl-2 and PCNA in various morphological lesions. (A) A significant difference in Bcl-2 was noted among the four different tissue types $(\mathrm{P}<0.0001)$. The pair-wise comparison showed a significant difference in Bcl-2 expression in SA vs. PIA/PAH lesions (P<0.0001); SA vs. HGPIN $(\mathrm{P}=0.012)$; PIA/PAH vs. HGPIN ( $\mathrm{P}=0.002)$; and PIA/PAH vs. cancer $(\mathrm{P}=0.0009)$. (B) A significant difference in PCNA expression was noted among the four different tissue types $(\mathrm{P}<0.0001)$. The pair-wise comparison revealed a significant difference in PCNA expression in $\mathrm{SA}$ vs. $\mathrm{PIA} / \mathrm{PAH}(\mathrm{P}=0.0007)$; $\mathrm{SA}$ vs. HGPIN ( $\mathrm{P}=0.002)$; SA vs. cancer $(\mathrm{P}=0.002)$; PIA/PAH vs. HGPIN ( $\mathrm{P}=0.004)$; PIA/PAH vs. cancer ( $\mathrm{P}=0.0004)$; and HGPIN vs. cancer ( $\mathrm{P}=0.004)$. $\mathrm{PCNA}$, proliferating cell nuclear antigen; SA, simple atrophy; PIA, proliferative inflammatory atrophy; PAH, post-atrophic hyperplasia; HGPIN, high-grade prostatic intraepithelial neoplasia; SEM, standard error of the mean.
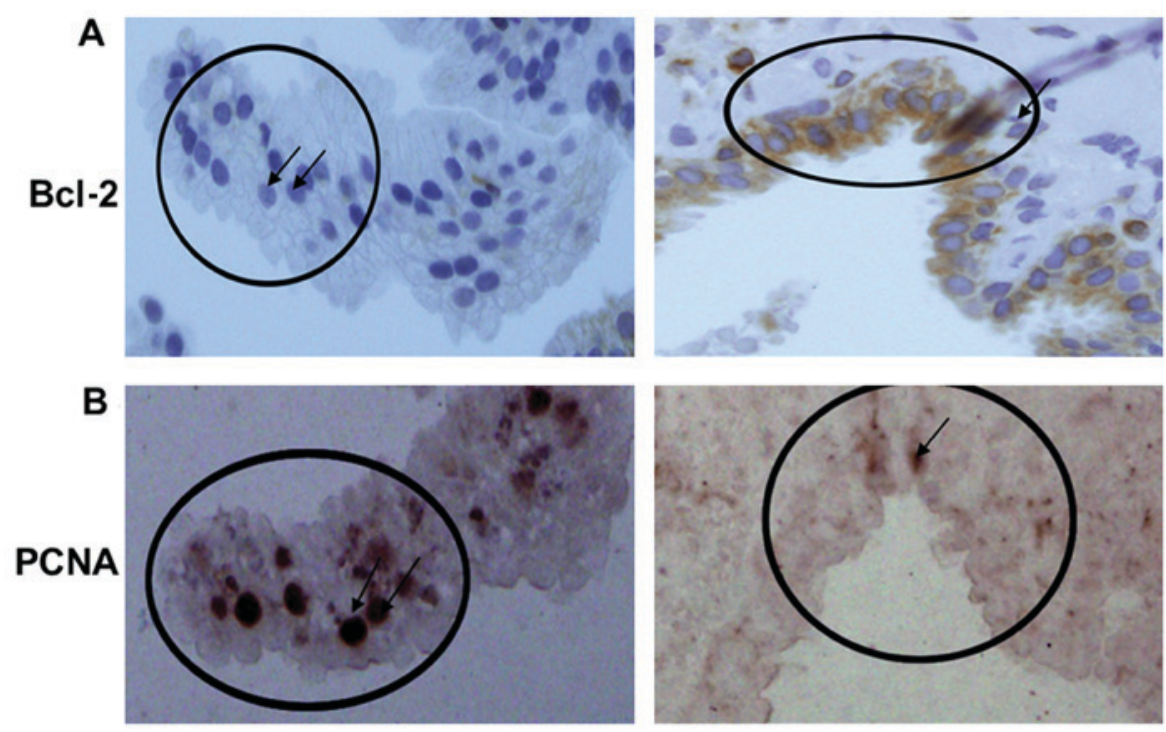

Figure 4. Needle-biopsy specimens immunostained for Bcl-2 and PCNA in serial sections. Left and right panels demonstrate serial section from 2 different prostate needle biopsy specimens. (A) Epithelial cells show weak Bcl-2 staining (left panel) and heavy cytoplasmic staining for Bcl-2 (right panel), (B) Needle-biopsy specimens immunostained for PCNA within the serial sections of the same specimen. Intense PCNA in cells which do not express Bcl-2 (left panel) whereas little-to-no expression of PCNA is observed in cells expressing Bcl-2 (right panel). Arrows showing cells expressing high PCNA but not $\mathrm{Bcl}-2$, and vice versa. PCNA, proliferating cell nuclear antigen.

\section{Discussion}

The purpose of the present study was to determine the association between epithelial cell survival and proliferation under the influence of chronic inflammation, and whether molecular changes may be an indicator of neoplastic progression. Prostate carcinogenesis is a continuous process with distinct stages of atrophy, hyperplasia, prostatic intraepithelial neoplasia and carcinoma, which can be identified on the basis of cellular morphology and topographical features (18-23). During the initiation of prostate cancer, most of the proliferation occurs in the luminal compartment rather than in the basal compartment (18-20). This shift is present in most of the carcinoma precursor lesions, including HGPIN. It has long been hypothesized that PIA may be a precursor of prostate cancer, as several studies have reported a morphological transition from PIA to HGPIN $(18,21)$. This suggestion is based on the following findings: i) Morphological overlap between PIA and HGPIN; ii) the phenotypes of many of the cells in PIA are most consistent with that of immature secretory-type cells, similar to that of the cells of HGPIN; and iii) PIA, HGPIN and carcinoma all occur with high prevalence in the peripheral zone and low prevalence in the central zone of the prostate. In the present study on needle-biopsy specimens, a close topographic 

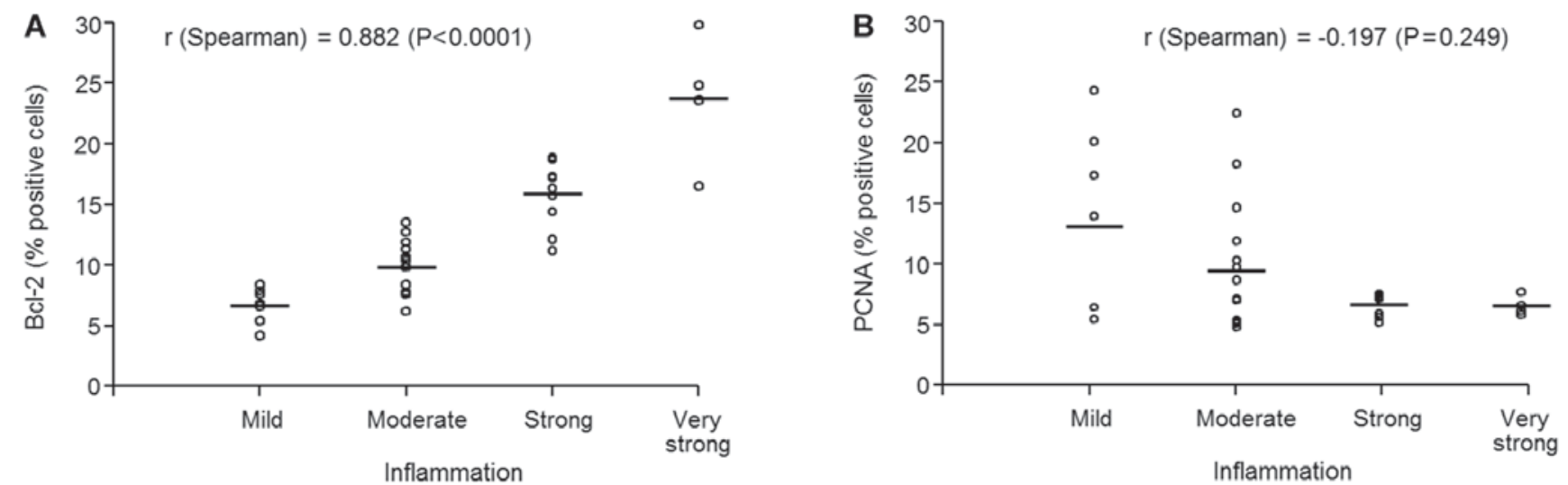

Figure 5. Scatter plot of inflammation vs. (A) Bcl-2 and (B) PCNA. A strong positive association between inflammation and expression level of Bcl-2 (r=0.882) was observed: The expression of $\mathrm{Bcl}-2$ identified $(\mathrm{r}=-0.197)$; however, this was not statistically significant $(\mathrm{P}=0.249)$. $\mathrm{r}$-values represent Spearman correlation coefficient. PCNA, proliferating cell nuclear antigen.

\section{CHRONIC INFLAMMATION AND CANCER DEVELOPMENT_DEFECTS IN SIGNALING}

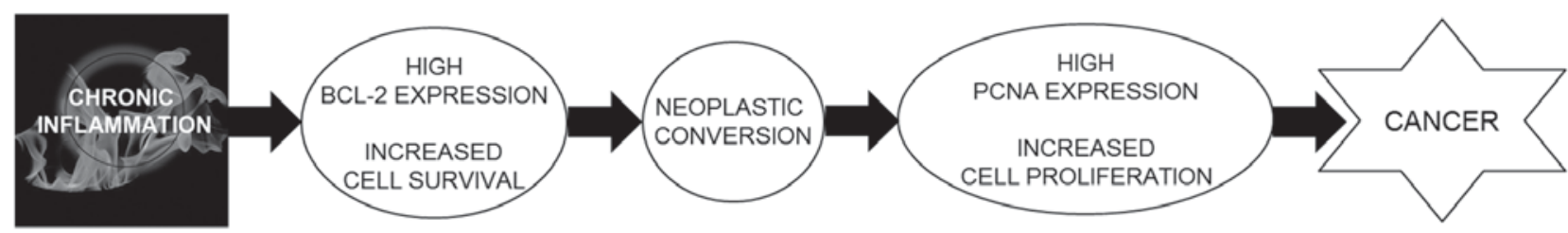

Figure 6. A hypothetical model showing how chronic inflammation leads to cancer development. Under the influence of chronic inflammation epithelial cells acquire increased survival with an increase in Bcl-2 expression. The survival signal alters the phenotype of these particular epithelial cells, which gain neoplastic characteristics, leading to precursors that may later acquire increased proliferation rate leading to cancer development and subsequent progression.

association between PIA/PAH and HGPIN was observed, in agreement with the findings in previous studies $(18,21)$.

As PIA is predominantly associated with inflammation, we speculated whether chronic inflammation may lead to neoplastic progression. It has been postulated that, under the influence of chronic inflammation, the proliferating epithelial cells of the prostate tend to adapt to the altered microenvironment by altering the delicate balance between cell death and proliferation (29). Chronic inflammation with the accumulation of lymphocyte infiltrate in the prostate may lead to repeated tissue damage and regeneration, with release or increased expression of cytokines, growth factors, and oncogenes, leading to a highly neoplastic state $(30,31)$. This has been observed by a marked increase in the Bcl-2 protein, a marker of cell survival, in PIA/PAH lesions by our group and several other investigators $(32,33)$. Based on immunohistochemical staining, the present study revealed that $\mathrm{Bcl}-2$ is upregulated in epithelial cells in areas of chronic inflammation. The $\mathrm{Bcl}-2$ protein is a product of the $B C L 2$ gene; it is a powerful inhibitor of apoptotic cell death and may lead to malignant transformation and tumor formation $(34,35)$. Bcl-2 expression in prostate cancer is associated with the androgen-independent phenotype (36). High expression of $\mathrm{Bcl}-2$ was also noted in the infiltrating immune cells in the present study. Further studies by De Marzo et al (37) have shown that protection from repeated oxidative or electrophilic DNA damage is achieved in PIA/PAH lesions by increased expression of glutathione S-transferase pi (GSTP1), which catalyzes the detoxification of reactive electrophiles and oxidants and therefore can have a protective effect against neoplastic transformation; by contrast, this does not occur in HGPIN and carcinoma (37). Further recent studies have shown that GSTP1 CpG island hypermethylation changes occur in a proportion of PIA/PAH lesions, providing evidence that at least some of these lesions harbor cells already initiated to progress to HGPIN and/or prostate adenocarcinoma $(38,39)$.

The rate of proliferation observed in the PIA lesion in the present study is comparatively less than that of HGPIN and cancer, suggesting that the majority of the cells have not achieved a neoplastic state. Therefore, it was investigated whether chronic inflammation may influence the development of cancer through the precursor HGPIN or PIA by rendering the cells to achieve a neoplastic state. Previous studies have shown that persistent chronic inflammation adjacent to PIA lesions may drive the epithelial cells to achieve increased survival (18-21). These may be regarded as initiated cells, and acquisition of further genetic alterations under the influence of continuous inflammation may drive the cells towards malignancy. It has been postulated that these initiated cells, over a period of time, may or may not be further influenced by inflammation. An independent ability to proliferate in an altered microenvironment may lead to cancer progression (18-21). This is evident from the increased proliferation rate, as demonstrated by intense PCNA staining, where the majority of the neoplastic/malignant cells exhibited a high proliferation index along with Bcl-2 staining. This suggestion is consistent with the previous findings, wherein some PIA/PAH lesions have been shown to acquire somatic chromosome 8 abnormalities 
and mutations in the tumor suppressor gene TP53 (genetic alterations that are associated with prostate cancer and HGPIN lesions) (40). Aberrant expression of these two molecules may lead to extended survival of neoplastic cells and increased likelihood of mutational aberrations, which are responsible for proliferation and aggressiveness.

Genetic alterations in the number of tumor suppressor genes, oncogenes, proliferation, apoptosis, and cellular stress response genes have been reported to be associated with HGPIN and prostate cancer $(41,42)$. In the present study, a strong association of PIA/PAH lesions with chronic inflammation was demonstrated, which seems to predispose cells to neoplastic development in the prostate. Furthermore, an inverse correlation between Bcl-2 and PCNA in the glandular epithelial cells seems to indicate that extended survival and apoptosis inhibition by $\mathrm{Bcl}-2$, and low proliferation rate under the influence of low-grade persistent inflammation, may promote malignant transformation. Fig. 6 illustrates this hypothetical model. However, broader studies of the apoptosis-regulatory proteins and proliferative proteins should be performed in an effort to elucidate the relationship between inflammation and neoplastic progression. In the present study, we attempted to minimize the pitfalls by categorizing specimens into four different subcategories (SA, PIA/PAH, HGPIN and cancer) associated with uniformly high chronic inflammation. Taken together, the findings of the present study suggest that persistent chronic inflammation is a common distinct entity resulting in increased survival of cells, and facilitates neoplastic development leading to a state of increased proliferation.

In conclusion, the present study identifies chronic inflammation as a contributor to neoplastic progression of prostate epithelial cells. Additional studies are required to illustrate the molecular/genetic alterations that occur during the events of inflammation that could lead to disease progression.

\section{Acknowledgements}

The original study from the authors' laboratory outlined in this review was supported by VA Merit Review (1I01BX002494), United States Public Health Service Grants (RO1CA108512, R21CA193080 and R03CA186179) and a Department of Defense grant (W81XWH-15-1-0558 awarded to S.G).

\section{References}

1. Wang $\mathrm{K}$ and Karin M: Tumor-Elicited Inflammation and colorectal cancer. Adv Cancer Res 128: 173-196, 2015.

2. Berasain C, Castillo J, Perugorria MJ, Latasa MU, Prieto J and Avila MA: Inflammation and liver cancer: New molecular links. Ann N Y Acad Sci 1155: 206-221, 2009.

3. Kundu JK and Surh YJ: Inflammation: Gearing the journey to cancer. Mutat Res 659: 15-30, 2008.

4. Umbehr MH, Gurel B, Murtola TJ, Sutcliffe S, Peskoe SB, Tangen CM, Goodman PJ, Thompson IM, Lippman SM, Lucia MS, et al: Intraprostatic inflammation is positively associated with serum PSA in men with PSA $<4$ ng ml(-1), normal DRE and negative for prostate cancer. Prostate Cancer Prostatic Dis 18: 264-269, 2015.

5. Sfanos KS, Hempel HA and De Marzo AM: The role of inflammation in prostate cancer. Adv Exp Med Biol 816: 153-181, 2014

6. Cheng I, Witte JS, Jacobsen SJ, Haque R, Quinn VP, Quesenberry CP, Caan BJ and Van Den Eeden SK: Prostatitis, sexually transmitted diseases, and prostate cancer: The California Men's Health Study. PLoS One 5: e8736, 2010.
7. Porcaro AB, Rubilotta E, Petrozziello A, Ghimenton C, Migliorini F, Zecchini Antoniolli S, Lacola V, Monaco C, Curti P, Cavalleri S, et al: Chronic inflammation of the prostate type IV with respect to risk of prostate cancer. Arch Ital Urol Androl 86: 208-211, 2014

8. Adamczyk P, Wolski Z, Butkiewicz R, Nussbeutel J and Drewa T: Inflammatory changes in biopsy specimens from patients with suspected prostate cancer. Cent European J Urol 66: 256-262, 2013.

9. Vandersluis AD, Guy DE, Klotz LH, Fleshner NE, Kiss A, Parker C and Venkateswaran V: The role of lifestyle characteristics on prostate cancer progression in two active surveillance cohorts. Prostate Cancer Prostatic Dis 19: 305-310, 2016.

10. Discacciati A and Wolk A: Lifestyle and dietary factors in prostate cancer prevention. Recent Results Cancer Res 202: 27-37, 2014.

11. Gonzalez CA and Riboli E: Diet and cancer prevention: Contributions from the European Prospective Investigation into Cancer and Nutrition (EPIC) study. Eur J Cancer 46: 2555-2562, 2010.

12. Rybicki BA, Kryvenko ON, Wang Y, Jankowski M, Trudeau S, Chitale DA, Gupta NS, Rundle A and Tang D: Racial differences in the relationship between clinical prostatitis, presence of inflammation in benign prostate and subsequent risk of prostate cancer. Prostate Cancer Prostatic Dis 19: 145-150, 2016.

13. Mian OY, Khattab MH, Hedayati M, Coulter J, Abubaker-Sharif B, Schwaninger JM, Veeraswamy RK, Brooks JD, Hopkins L, Shinohara DB, et al: GSTP1 Loss results in accumulation of oxidative DNA base damage and promotes prostate cancer cell survival following exposure to protracted oxidative stress. Prostate 76: 199-206, 2016.

14. Vasto S, Carruba G, Candore G, Italiano E, Di Bona D and Caruso C: Inflammation and prostate cancer. Future Oncol 4: 637-645, 2008

15. Nguyen DP, Li J, Yadav SS and Tewari AK: Recent insights into $\mathrm{NF}-\kappa \mathrm{B}$ signaling pathways and the link between inflammation and prostate cancer. BJU Int 114: 168-176, 2014.

16. MacLennan GT, Eisenberg R, Fleshman RL, Taylor JM, Fu P, Resnick MI and Gupta S: The influence of chronic inflammation in prostatic carcinogenesis: A 5-year followup study. J Urol 176: 1012-1016, 2006.

17. Kulac I, Gumuskaya B, Drake CG, Gonzalez B, Arnold KB, Goodman PJ, Kristal AR, Lucia MS, Thompson IM, Isaacs WB, et al: Peripheral zone inflammation is not strongly associated with lower urinary tract symptom incidence and progression in the placebo arm of the prostate cancer prevention trial. Prostate 76: 1399-1408, 2016.

18. Wang W, Bergh A and Damber JE: Morphological transition of proliferative inflammatory atrophy to high-grade intraepithelial neoplasia and cancer in human prostate. Prostate 69: 1378-1386, 2009.

19. Woenckhaus $\mathbf{J}$ and Fenic I: Proliferative inflammatory atrophy: A background lesion of prostate cancer? Andrologia 40: 134-137, 2008.

20. Chrisofos M, Papatsoris AG, Lazaris A and Deliveliotis C: Precursor lesions of prostate cancer. Crit Rev Clin Lab Sci 44: 243-270, 2007.

21. Vral A, Magri V, Montanari E, Gazzano G, Gourvas V, Marras E and Perletti G. Topographic and quantitative relationship between prostate inflammation, proliferative inflammatory atrophy and low-grade prostate intraepithelial neoplasia: A biopsy study in chronic prostatitis patients. Int J Oncol 41: 1950-1958, 2012.

22. Postma R, Schröder FH and van der Kwast TH: Atrophy in prostate needle biopsy cores and its relationship to prostate cancer incidence in screened men. Urology 65: 745-749, 2005.

23. Servian P, Celma A, Planas J, Placer J, de Torres IM, Olivan M and Morote J: Clinical significance of proliferative inflammatory atrophy finding in prostatic biopsies. Prostate 75: 1669-1675, 2015.

24. Kelly PN and Strasser A: The role of Bcl-2 and its pro-survival relatives in tumourigenesis and cancer therapy. Cell Death Differ 18: 1414-1424, 2011.

25. Strzalka W and Ziemienowicz A: Proliferating cell nuclear antigen (PCNA): A key factor in DNA replication and cell cycle regulation. Ann Bot 107: 1127-1140, 2011.

26. Bostwick DG and Cheng L: Precursors of prostate cancer Histopathology 60: 4-27, 2012.

27. Cheng L, Montironi R, Bostwick DG, Lopez-Beltran A and Berney DM: Staging of prostate cancer. Histopathology 60: 87-117, 2012. 
28. Shukla S, MacLennan GT, Fu P, Patel J, Marengo SR, Resnick MI and Gupta S: Nuclear factor-kappaB/p65 (Rel A) is constitutively activated in human prostate adenocarcinoma and correlates with disease progression. Neoplasia 6: 390-400, 2004.

29. Henrique R, Jerónimo C, Teixeira MR, Hoque MO, Carvalho AL, Pais I, Ribeiro FR, Oliveira J, Lopes C and Sidransky D: Epigenetic heterogeneity of high-grade prostatic intraepithelial neoplasia: Clues for clonal progression in prostate carcinogenesis. Mol Cancer Res 4: 1-8, 2006.

30. Nguyen DP, Li J and Tewari AK: Inflammation and prostate cancer: The role of interleukin 6 (IL-6). BJU Int 113: 986-992, 2014.

31. Taverna G, Pedretti E, Di Caro G, Borroni EM, Marchesi F and Grizzi F: Inflammation and prostate cancer: Friends or foe? Inflamm Res 64: 275-86, 2015.

32. Wang W, Bergh A and Damber JE: Chronic inflammation in benign prostate hyperplasia is associated with focal upregulation of cyclooxygenase-2, Bcl-2 and cell proliferation in the glandular epithelium. Prostate 61: 60-72, 2004.

33. Gerstenbluth RE, Seftel AD, MacLennan GT, Rao RN, Corty EW, Ferguson K and Resnick MI: Distribution of chronic prostatitis in radical prostatectomy specimens with up-regulation of bcl-2 in areas of inflammation. J Urol 167: 2267-2270, 2002.

34. Azad N, Iyer A, Vallyathan V, Wang L, Castranova V, Stehlik C and Rojanasakul Y: Role of oxidative/nitrosative stress-mediated $\mathrm{Bcl}-2$ regulation in apoptosis and malignant transformation. Ann N Y Acad Sci 1203: 1-6, 2010.

35. Medan D, Luanpitpong S, Azad N, Wang L, Jiang BH, Davis ME, Barnett JB, Guo L and Rojanasakul Y: Multifunctional role of Bcl-2 in malignant transformation and tumorigenesis of Cr(VI)-transformed lung cells. PLoS One 7: e37045, 2012.
36. van Soest RJ, van Royen ME, de Morrée ES, Moll JM, Teubel W, Wiemer EA, Mathijssen RH, de Wit R and van Weerden WM: Cross-resistance between taxanes and new hormonal agents abiraterone and enzalutamide may affect drug sequence choices in metastatic castration-resistant prostate cancer. Eur J Cancer 49: 3821-3830, 2013.

37. De Marzo AM, Marchi VL, Epstein JI and Nelson WG: Proliferative inflammatory atrophy of the prostate: Implications for prostatic carcinogenesis. Am J Pathol 155: 1985-1992, 1999.

38. Kanwal R, Pandey M, Bhaskaran N, Maclennan GT, Fu P, Ponsky LE and Gupta S: Protection against oxidative DNA damage and stress in human prostate by glutathione $\mathrm{S}$-transferase P1. Mol Carcinog 53: 8-18, 2014.

39. Schnekenburger M, Karius T and Diederich M: Regulation of epigenetic traits of the glutathione S-transferase P1 gene: From detoxification toward cancer prevention and diagnosis. Front Pharmacol 5: 170, 2014.

40. Crundwell MC, Chughtai S, Knowles M, Takle L, Luscombe M, Neoptolemos JP, Morton DG and Phillips SM: Allelic loss on chromosomes 8p, 22q and 18q (DCC) in human prostate cancer. Int J Cancer 69: 295-300, 1996.

41. Tapia-Laliena MA, Korzeniewski N, Hohenfellner M and Duensing S: High-risk prostate cancer: A disease of genomic instability. Urol Oncol 32: 1101-1107, 2014.

42. Schrecengost R and Knudsen KE: Molecular pathogenesis and progression of prostate cancer. Semin Oncol 40: 244-258, 2013. 